Commentary

\title{
Africa and the Covid-19 Information Framing Crisis
}

\author{
George Ogola \\ School of Journalism, Media and Performance, University of Central Lancashire, Preston, M11 3NU, UK; \\ E-Mail: googola@uclan.ac.uk
}

Submitted: 1 May 2020 | Accepted: 18 May 2020 | Published: 26 June 2020

\begin{abstract}
Africa faces a double Covid-19 crisis. At once it is a crisis of the pandemic, at another an information framing crisis. This article argues that public health messaging about the pandemic is complicated by a competing mix of framings by a number of actors including the state, the Church, civil society and the public, all fighting for legitimacy. The article explores some of these divergences in the interpretation of the disease and how they have given rise to multiple narratives about the pandemic, particularly online. It concludes that while different perspectives and or interpretations of a crisis is not necessarily wrong, where these detract from the crisis itself and become a contestation of individual and or sector interests, they birth a new crisis. This is the new crisis facing the continent in relation to the pandemic.
\end{abstract}

\section{Keywords}

Africa; Coronavirus; Covid-19; crisis; health journalism; misinformation; news framing

\section{Issue}

This commentary is part of the issue "Health and Science Controversies in the Digital World: News, Mis/Disinformation and Public Engagement" edited by An Nguyen (Bournemouth University, UK) and Daniel Catalan (University Carlos III of Madrid, Spain).

(C) 2020 by the author; licensee Cogitatio (Lisbon, Portugal). This article is licensed under a Creative Commons Attribution 4.0 International License (CC BY).

\section{Introduction}

Much of Africa is in the grip of a double Covid-19 crisis. It is a crisis of the pandemic as well as an information framing crisis. Public health messaging is complicated by a mix of competing framings of the pandemic by a number of actors including the state, the Church, civil society, the public and many others. The narrative around the Covid-19 pandemic in Africa is therefore a decidedly complex one. It is a multi-faceted narrative largely informed by the tensions between these competing sites of 'knowledges' in the continent all seemingly fighting for legitimacy.

\section{Politics and the Framing of the Pandemic}

The Covid-19 pandemic has been foremost a political story. It has exposed a number of weak healthcare systems in several countries in the continent, just as it has underscored the advantages of having well-developed community health care structures in others such as
South Africa. The investment in health care infrastructure remains critically low across the continent but ironically against the background of a worryingly heavy disease burden (Mostert et al., 2015). This has made many African countries particularly susceptible to the Coronavirus. But where poor health systems have been exposed, the default response from governments has been denial, secrecy, even official misinformation, primarily because of its political implications. This has in turn encouraged the manufacturing of alternative narratives of the Covid-19 crisis, particularly online.

In recent years online media spaces have assumed significant communicative, cultural and political agency in Africa (Ogola, 2019). Platform media such as Facebook, Twitter and messaging apps such as WhatsApp have become critical political spaces for the creation, contestation and dissemination of public information. They are sites used as much by none-state actors as they are by the state. In a country such as Kenya, for example, where the state plays the role of regulator and active actor in these online spaces, the government is using official 
Twitter handles and hashtags to communicate state policy on the pandemic, post updates on infection rates, deaths and to rally the country around its public health messaging. The hashtag \#komeshacorona (Kiswahili for 'Stop Corona'), for example, has been created for purposes of public information but more crucially, for information management regarding the pandemic.

It is this latter aspect that is furiously contested. Online platforms have in recent years provided civil society and the general public important tools and spaces to contest such management and to call governments to account. It is notable therefore that in response to such official government hashtags regarding the pandemic, Kenyans on Twitter (commonly referred to as KOT) have created their alternative hashtags to anchor their criticism of government responses to the crisis. Using the hashtag \#covid_19ke KOT have demanded a much better response to the pandemic, pointing out state malpractices and criticising interventions such as the lockdowns, which have been notably militarised as curfews.

Overall, public health messaging by governments in many parts of the continent have been undermined by public distrust following years of official misinformation practices. Public reaction to government information thus tends to be one of apprehension and ambivalence as many people are aware that these governments have often been interested foremost in the (political) control of the message than the message itself.

\section{Misinformation and Disinformation Practices}

When the state cannot be trusted on important national issues such as an international health pandemic, misinformation and disinformation practices proliferate. Pandemics create fear, anxiety and confusion and therefore fuel a determination to seek information and clarity. According to a recent Reuters Institute for the Study of Journalism report, disinformation and misinformation take multiple forms-from reconfigurations of information to complete fabrication of stories (Brennen, Simon, Howard, \& Nielsen, 2020). These abound in relation to Covid-19. A number of misinformation and disinformation actors have appropriated well known communication traditions in the continent such as the use of rumours, which are generally considered to be subversive to offer alternative framings of the pandemic on platforms such as Twitter, WhatsApp and Facebook. It is important to reiterate that in Africa, rumour has historically been considered a site of truth (Ellis, 2002). It was and remains a means through which state narratives are routinely subverted and dismembered, where alternative scripts are written and where silent stories are made legible. In fact, even the state is known to generate its own rumours.

Rumour finds particular relevance and utility in an environment in which there is not only widespread distrust of the state as a source of credible information but also where much of the mainstream media similarly suffer a trust deficit, a point I return to later in this commen- tary. Alternative framings of the pandemic have therefore proliferated in the form of rumours mainly in closed networks such as WhatsApp and on platforms such as Facebook. These are the two most commonly used online platforms in the continent. Importantly, these are generally networks of shared socialities and therefore users are particularly vulnerable to mis/disinformation because they receive such information from people they know. Questions have, for example, been raised about government data on the number of Covid-19 infection and mortality rates in Kenya, Tanzania, Uganda, Ethiopia, Nigeria and several other African countries. People have therefore come up with alternative data and are circulating these within their networks.

In Tanzania, which is one of a handful of countries that have only grudgingly acknowledged the severity of the pandemic, the government's desire to control public information relating to the pandemic has fuelled an infodemic of misinformation and disinformation online. The Magufuli government holds a tight rein on the mainstream media and journalists who have questioned state policy relating to the pandemic have been threatened and or arrested.

In the absence of credible official information and seeming state intransigence, rumours attempting to show the severity of the pandemic have been widely circulated on social media. Among these have been videos of alleged bodies of the victims of Covid-19 dumped on the streets and many others buried in the night. One such video, circulated mainly in WhatsApp groups and Facebook, turned out to be a 2014 footage of dead bodies of refugees washed ashore on the Libyan coast. The refugees had tragically died trying to cross the Mediterranean Sea in their attempt to get to Europe.

These stories and videos while subverting the state's narrative about the crisis, simultaneously create a climate of fear and a powerful sense of helplessness making individuals even more susceptible to disinformation practices. Such fear feed already existing attitudes relating to pandemics thereby stigmatising victims. They recreate the horror of pandemics that have previously afflicted the continent such as Ebola and HIV. The containment of these diseases was undermined by the resultant social stigma described by Davtyan, Brown, and Folayan (2014, p. 2) as "stressors with incapacitating consequences." Those with symptoms avoided seeking medical help thus either dying or continuing to spread infections. In Kenya, the government has been forced to appeal to the public to welcome back into the community those who have recovered from Covid-19. A suicide has been reported of a survivor of the disease in the country. Meanwhile, circulating videos of burials conducted in the night, reportedly of those who have succumbed to the disease by state officials, is feeding the stigma as it also solidifies the criticism and distrust of the state.

Misinformation is also being attributed to religious leaders, many with considerable followers online. Several religious leaders have elected to give a spiri- 
tual interpretation of the pandemic. Across the continent there are religious leaders appealing to adherents to pray for their salvation from the disease and at the same time to emphasise their 'exceptionalism.' From leaders such as the Nigerian Islamic scholar Abubakr Imam Aliagan-who has claimed that Muslims are immune from Covid-19-to Protestant Ethiopian Prophet Israel Dansa-who told his followers that he "saw the virus completely burned into ashes" with the power of his prayer - the pandemic has been framed as a battle between faith and science (Lichtenstein, Ajayi, \& Egbunike, 2020). Most of these religious leaders have YouTube channels where they post their sermons and messages relating to the pandemic.

\section{Health Journalism and Making Sense of the Pandemic}

Contributing to this public susceptibility to dis/misinformation practices is the failure of mainstream media to effectively play its normative roles. Mainstream media in the continent finds itself in a difficult space. Structurally, it operates in an environment in which its independence is fundamentally compromised primarily by its reliance on the state as its single largest advertiser (Ogola, 2019). There is only so far it can go in destabilising its affective relationship with the state. But it also suffers from considerable institutional deficiencies. For example, with few exceptions, in regard to the coverage of Covid-19, it has become standard practice for media organisations across the continent to simply reproduce government press statements about the pandemic. This has been problematic not only because of the relative vagueness and unreliability of much of the information, but also because the lack of broader contextual details make such information discursively distant to local audiences. One of the key problems arising from the coverage of this pandemic in Africa has been the reproduction of internationalised stock phrases, many contextually unhelpful. There is very little involvement of African scientists interpreting the pandemic in a relatable local vocabulary, rooted in local everyday practices and experiences. In the absence of these local translations, concepts such as 'flattening the curve,' 'social distancing,' 'case fatality rate,' 'RO' and others are reproduced with barely any relatable references or context provided.

As local audiences are looking for stories that are relevant to their everyday experiences, social media is providing many such stories, some true but a good number fabricated. These range from conspiracy theories relating to the alleged immunity of Africans to Covid-19 and the role of $5 \mathrm{G}$ technology in the spread of the pandemic to stories about easily available traditional medicines that have been used to cure the disease.

The paucity of relatable stories about the pandemic in mainstream media is partly a result of the lack of investment in health journalism by media organisations in the continent. Resource limitations have forced most media organisations to focus on stories and areas that maximise audience and advertising revenues. In most cases the focus is usually on entertainment (in the case of broadcast media) and politics (in the case of newspapers). Health journalism and, more broadly, science journalism do not therefore command editorial urgency as they are seen to attract little or no advertising. Indeed most health pull-outs in many newspapers across the continent are funded by the state, non-governmental organisations or philanthropic foundations with an interest in public health, such as the Melinda Gates Foundation. Health journalists also tend to be general beat or political reporters, often without the necessary expertise to critically engage with health stories. Complex health stories thus tend to be narrated primarily as political stories. It is no coincidence therefore that mainstream media coverage of the Covid-19 pandemic has focused mainly on the political impact of the crisis than on the understanding of the pandemic as a health crisis in need of scientific interventions too.

This political domination of the coverage of the pandemic has also revealed a worrying lack of public engagement by local African scientists in a number of countries. It is arguable that they should have been at the forefront of providing distinctly local and relatable interpretations of the pandemic.

The multiple framings of the Covid-19 pandemic brings into sharp relief the state of health communication in Africa. While having different perspectives and/or interpretations of a crisis is not necessarily wrong, perhaps even inevitable, where such framings detract from the crisis itself and become a contestation of individual and/or sector interests, they birth a new crisis. This is the double crisis Africa must now resolve.

\section{Acknowledgments}

I would like to express my appreciation to An Nguyen for his invitation to contribute to this issue at a time when the subject is of such considerable relevance and importance.

\section{Conflict of Interests}

The author declares no conflict of interests.

\section{References}

Brennen, J. S., Simon, F., Howard, P. N., \& Nielsen, R. K. (2020). Types, sources and claims of Covid-19 misinformation. Oxford: Reuters Institute for the Study of Journalism. Retrieved from https://reutersinstitute. politics.ox.ac.uk/types-sources-and-claims-covid-19misinformation

Davtyan, M., Brown, B., \& Folayan, M. O. (2014). Addressing Ebola-related stigma: Lessons learned from HIV/AIDS. Global Health Action, 7(1). https://doi.org/ 10.3402/gha.v7.26058 
Ellis, S. (2002). Writing histories of contemporary Africa. The Journal of African History, 43(1), 1-26.

Lichtenstein, A., Ajayi, R., \& Egbunike, N. (2020). Across Africa, Covid-19 heightens tension between faith and science. Global Voices. Retrieved from https:// globalvoices.org/2020/03/25/across-africa-covid19-heightens-tension-between-faith-and-science Mostert, S., Njuguna, F., Olbara, G., Sindano, S.,
Sitaresmi, M. N., Supriyadi, E., \& Kaspers, G. (2015). Corruption in health-care systems and its effect on cancer care in Africa. The Lancet, 16(8), 394-404.

Ogola, G. (2019). \#Whatwouldmagufulido? Kenya's digital "practices" and "individuation" as a (non)political act. Journal of Eastern African Studies, 13(1), 124-139.

\section{About the Author}

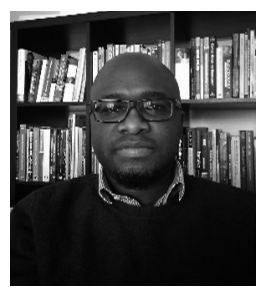

George Ogola is a Reader in Journalism in the School of Journalism, Media and Performance at the University of Central Lancashire, UK. He has published widely on the impact of emerging digital technologies on journalism and politics in Africa and on the interface between popular media and popular culture, particularly within the context of power performances in Kenya. 